\title{
Mental practice as a novel learning strategy for donning and doffing personal protective equipment during the COVID-19 pandemic
}

\author{
Jamie Riggs (1), MD*; Melissa McGowan, $\mathrm{MHK}^{\dagger}$; Andrew Petrosoniak, MD, MSc ${ }^{*}$; \\ Christopher Hicks, MD, MEd ${ }^{*+}$
}

\begin{abstract}
The coronavirus disease 2019 (COVID-19) pandemic presents challenges to the effective use of personal protective equipment, including equipment shortages, staff unfamiliarity, and physical distancing. Mental practice has been used as an alternative learning strategy in medicine for the development of technical skills. We developed educational materials with the aim of using mental practice to overcome these challenges and increase provider skill and confidence with the use of personal protective equipment. A mental practice script integrating cognitive, kinesthetic, and visual cues with a list of procedural steps was created and iteratively refined. To allow the use of this tool by providers unfamiliar with the principles of mental practice, accompanying explanatory materials were created and disseminated widely through the Free Open Access Medical education (FOAMed) community. By creating easily accessible resources to facilitate effective mental practice, providers may be able to increase their skill and comfort with the procedure while conserving personal protective equipment and respecting physical distancing guidelines.
\end{abstract}

\section{RÉSUMÉ}

L'arrivée de la pandémie de COVID-19 a soulevé bien des difficultés quant à l'usage approprié de l'équipement de protection individuelle (EPI), difficultés liées notamment à la pénurie de matériel, au manque d'expérience du personnel et à la distance physique. L'imagerie mentale est déjà un moyen d'apprentissage utilisé en médecine pour l'acquisition de compétences techniques. L'équipe de travail a donc élaboré du matériel didactique, fondé sur l'imagerie mentale, afin de permettre aux fournisseurs de soins de surmonter ces difficultés, d'acquérir les habiletés techniques nécessaires au port de l'EPI et d'avoir confiance en eux-mêmes quant à l'utilisation de ce nouveau matériel. Un algorithme de répétition mentale, intégrant à la fois des éléments cognitifs, kinesthésiques et visuels, et accompagné d'une liste d'étapes procédurales a d'abord été élaboré, puis amélioré au fil du temps. Afin de faciliter la tâche aux personnes connaissant peu les principes de l'imagerie mentale, l'équipe a aussi préparé du matériel explicatif et l'a diffusé à grande échelle au sein de la communauté FOAM. Les ressources étant facilement consultables pour favoriser une répétition mentale efficace, les fournisseurs de soins peuvent développer leur habileté à utiliser I'EPI et se sentir plus à l'aise avec la procédure, tout en ménageant le matériel lui-même et en respectant la distance physique.

Keywords: Mental practice, pandemic, personal protective equipment

\section{INTRODUCTION}

Personal protective equipment (PPE) is of critical importance to allow healthcare providers to care for patients safely and effectively. The coronavirus disease
2019 (COVID-19) pandemic has presented numerous new challenges to clinical care teams, who have been confronted by possible shortages of PPE as they face a novel respiratory virus. ${ }^{1}$ In jurisdictions with high numbers of COVID-19-related visits, a shortage of staff has

From the *Division of Emergency Medicine, Department of Medicine, University of Toronto, Toronto, ON; and ${ }^{\dagger}$ Department of Emergency Medicine, St. Michael's Hospital, Toronto, ON.

Correspondence to: Dr. Christopher Hicks, St. Michael's Hospital, Department of Emergency Medicine, 30 Bond Street, 1-008e Shuter Wing, Toronto, ON M5B 1W8; Email: chrismikehicks@gmail.com.

(c) Canadian Association of Emergency Physicians 2020

CJEM 2020;22(5):614-616

DOI 10.1017/cem.2020.432 
meant that clinicians from other specialties have been called on to care for patients in new environments. ${ }^{2}$ Each of these factors presents a challenge to the proper use of PPE, as staff unfamiliar with the process of donning and doffing safely must be trained appropriately while balancing the need to conserve PPE for direct patient care.

Mental practice, defined as the cognitive rehearsal of a skill without gross physical movement, ${ }^{3}$ has been shown to be an effective method of learning and maintaining complex physical skills in medicine. ${ }^{4}$ The goal of mental practice is to generate mental representations of the skill being practised, which has been shown to be as effective as additional physical practice for selected surgical skills. ${ }^{5}$ The mental practice process has typically involved a period of relaxation, followed by the recitation of a standardized script, which includes visual, kinesthetic, and cognitive cues to facilitate the generation of rich mental representations of the procedure. ${ }^{5}$ Mental practice has also been demonstrated to reduce the stress reaction associated with performing procedures. ${ }^{6}$ Mental practice, to our knowledge, has not been applied to PPE use but may allow for healthcare providers to become more comfortable with the procedure when physical practice is not feasible.

\section{PURPOSE}

We developed a mental practice script and process to facilitate the development of skills for donning and doffing PPE.

\section{DESCRIPTION OF INNOVATION}

The development of the mental practice script was based on a framework used to create similar scripts for surgical procedures. ${ }^{7}$ The list of procedural steps for donning and doffing PPE for aerosol-generating medical procedures was provided by Infection Prevention and Control (IPAC) at a Canadian teaching hospital. ${ }^{8}$ The initial draft was developed by identifying visual, kinesthetic, and cognitive cues at each step. These cues were then integrated into a cohesive narrative script, as outlined in Figure 1. In this case, the cues were added by an author (JR) with experience donning and doffing PPE. Iterative changes were made to the initial script based on feedback from two authors $(\mathrm{AP}, \mathrm{CH})$ with expertise in simulation

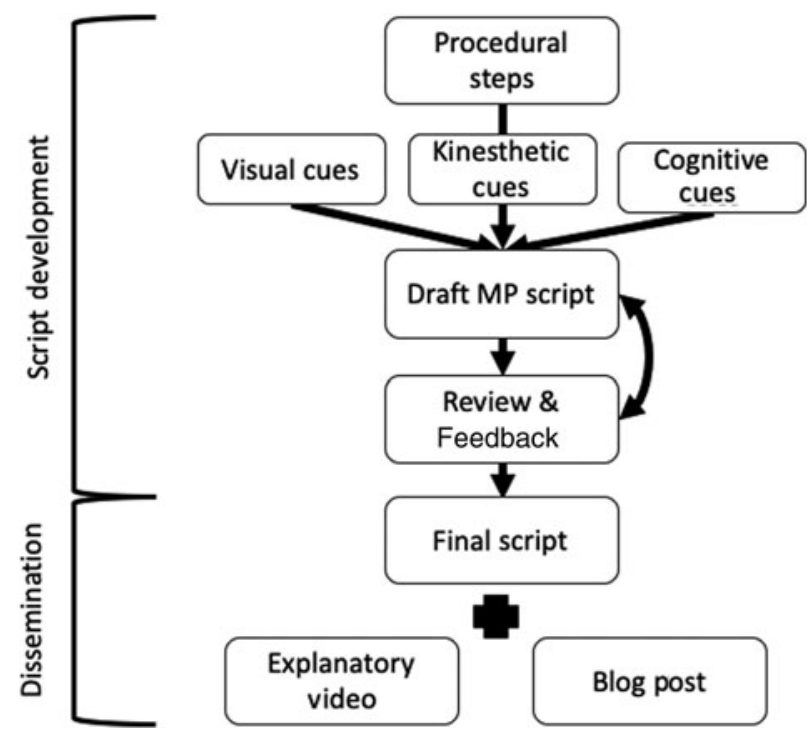

Figure 1. Outline of the process of script development and dissemination of knowledge.

and medical education, and experience donning and doffing PPE. Modifications to the script were made to accommodate differing requirements for PPE for various clinical situations, and to improve the generalizability of the script. The full script is available as a supplement to this article.

We applied a 4-step process for the implementation of mental practice for PPE donning and doffing. These steps provide a foundation for individuals to customize their own mental practice routine while incorporating tools, such as a pre-written script. This stepwise approach includes:

1. Learning the steps for donning and doffing PPE as laid out by each individual institution's IPAC. Here we suggest using instructional videos or other materials provided by each provider's institution.

2. Reflecting on previous experiences using PPE, paying attention to cognitive, kinesthetic, and visual cues that can add fidelity to the mental representation of the procedure.

3. Beginning a mental practice routine using aids, such as audio instructions and scripts.

4. Adding fidelity with simple steps, such as assuming a standing position while practising.

We recognize that mental practice may be a new concept for many clinicians, and, as such, we developed a 
short ( $\sim 3$-minute) video along with accompanying written materials. We posted this as open access content via https://emcrit.org/emcrit/mastering-ppe/. ${ }^{9}$ In 52 days of online availability, the blog post and resources were viewed 12,180 times.

\section{DISCUSSION}

The COVID-19 pandemic presents unique challenges for healthcare providers learning how to use PPE. ${ }^{1,2}$ Mental practice has been used to teach a number of technical skills in medicine ${ }^{4,5}$ but has not been used as a tool to facilitate safe PPE use. Here, we describe the creation of learning materials to allow providers previously unfamiliar with mental practice to effectively integrate these principles into their learning. Our script was developed on the premise that it be accessible and useful to any healthcare provider and that it be easily applied to daily practice without the need for special equipment or the involvement of other people.

Limited availability of PPE has been a concern for many healthcare organizations. Using mental practice eliminates the need for any physical PPE, conserving it for clinical use. Similarly, mental practice eliminates the need for healthcare providers to physically attend learning sessions, an important consideration that allows for the maintenance of physical distancing measures while allowing providers to continue to practise independently. Previous work suggests that mental practice can be an effective way of reducing the stress response associated with performing surgical procedures. ${ }^{6}$ By increasing provider familiarity with the procedure, mental practice may reduce the stress involved in performing what may be seen as a high-consequence procedure.

It is important to acknowledge the limitations of mental practice for learning critical procedures, such as PPE use. Staff members may have vastly different experiences and training in PPE use, and therefore this may not be an appropriate strategy for every member of the healthcare team. Although mental practice may represent a useful supplement to physical practice, opportunities to practise the procedure with real PPE under the guidance of experienced instructors will continue to be the most important form of learning for this procedure. The learning materials described here aim to provide sufficient cues to allow for effective mental practice, but it is foreseeable that generating rich mental representations may be more difficult for those without previous experience using PPE.

\section{CONCLUSION}

We developed resources to allow healthcare providers to apply the principles of mental practice to the donning and doffing of PPE. This may provide a way to improve provider confidence and skill when opportunities for physical practice are limited.

Supplemental material: The supplemental material for this article can be found at https://doi.org/10.1017/cem.2020.432.

Acknowledgements: The authors thank Dr. Scott Weingart for providing statistics about the web-based dissemination of these resources.

Competing interests: None declared.

\section{REFERENCES}

1. Canadian Association of Emergency Physicians. Recommendations for PPE in the emergency department during COVID-19; 2020. Available at: https://caep.ca/covid-19/ (accessed April 28, 2020).

2. Government of Canada. COVID-19 pandemic guidance for the health care sector; 2020. Available at: https://www.canada. ca/en/public-health/services/diseases/2019-novel-coronavirusinfection/health-professionals/covid-19-pandemic-guidancehealth-care-sector.html\#a431 (accessed April 28, 2020).

3. Richardson A. Mental imagery. London: Routledge \& Kegan Paul; 1969.

4. Arora S, Aggarwal R, Sirimanna P, et al. Mental practice enhances surgical technical skills: a randomized controlled study. Ann Surg 2011;253(2):265-70.

5. Sanders CW, Sadoski M, Bramson R, Wiprud R, Van Walsum K. Comparing the effects of physical practice and mental imagery rehearsal on learning basic surgical skills by medical students. Am 7 Obstet Gynecol 2004;191(5):1811-4.

6. Arora S, Aggarwal R, Moran A, et al. Mental practice: effective stress management training for novice surgeons. $7 \mathrm{Am}$ Coll Surg 2011;212(2):225-33.

7. Arora S, Aggarwal R, Sevdalis N, et al. Development and validation of mental practice as a training strategy for laparoscopic surgery. Surg Endosc 2010;24(1):179.

8. Goffi A, Muller M. COVID-19 considerations for aerosol generating medical procedures. Unity Health; 2020. Available at: https://unityhealth.to/coronavirus-information-for-staff/ (accessed April 28, 2020).

9. Hicks C. EMCrit - mental practice in the COVID19 era: mastering PPE; 2020. Available at: https://emcrit.org/emcrit/ mastering-ppe/ (accessed April 29, 2020). 